\title{
Influence of uncertainties of the empirical models for inferring the E-region electric fields at the dip equator
}

\author{
Juliano Moro ${ }^{1 *}$ (D, Clezio Marcos Denardini², Laysa Cristina Araújo Resende ${ }^{2}$, Sony Su Chen² \\ and Nelson Jorge Schuch ${ }^{1}$
}

\begin{abstract}
Daytime E-region electric fields play a crucial role in the ionospheric dynamics at the geomagnetic dip latitudes. Due to their importance, there is an interest in accurately measuring and modeling the electric fields for both climatological and near real-time studies. In this work, we present the daytime vertical (Ez) and eastward (Ey) electric fields for a reference quiet day (February 7, 2001) at the São Luís Space Observatory, Brazil (SLZ, 2.31 $\left.{ }^{\circ} \mathrm{S}, 44.16^{\circ} \mathrm{W}\right)$. The component Ez is inferred from Doppler shifts of type II echoes (gradient drift instability) and the anisotropic factor, which is computed from ion and electron gyro frequencies as well as ion and electron collision frequencies with neutral molecules. The component Ey depends on the ratio of Hall and Pedersen conductivities and Ez. A magnetic field-line-integrated conductivity model is used to obtain the anisotropic factor for calculating $E z$ and the ionospheric conductivities for calculating Ey. This model uses the NRLMSISE-00, IRI-2007, and IGRF-11 empirical models as input parameters for neutral atmosphere, ionosphere, and geomagnetic field, respectively. Consequently, it is worth determining the uncertainties (or errors) in Ey and Ez associated with these empirical model outputs in order to precisely define the confidence limit for the estimated electric field components. For this purpose, errors of $\pm 10 \%$ were artificially introduced in the magnitude of each empirical model output before estimating Ey and Ez. The corresponding uncertainties in the ionospheric conductivity and electric field are evaluated considering the individual and cumulative contribution of the artificial errors. The results show that the neutral densities and temperature may be responsible for the largest changes in Ey and Ez, followed by changes in the geomagnetic field intensity and electron and ions compositions.
\end{abstract}

Keywords: Space weather, Equatorial aeronomy, E-region electric fields, Empirical models

\section{Introduction}

Ionospheric electric fields and their time variations play a dominant role in the ionospheric electrodynamic at low latitudes, especially during daytime at the E-region height in the low-latitude ionosphere (Denardini et al. 2013). The basic global mechanism that generates these electric fields in the ionosphere is known to be the global dynamo action of neutral winds. The zonal electric field $(E y)$, which is eastward (geographic coordinates) during daytime, controls vertical plasma transport in the

\footnotetext{
*Correspondence: juliano.moro@inpe.br; julianopmoro@gmail.com 1 Southern Regional Space Research Center (CRS/INPE), Av. Roraima, 5021, Santa Maria, RS 97110-970, Brazil

Full list of author information is available at the end of the article
}

low-latitude ionosphere (Fejer 1997). It also forms a critical input to models that predict ionospheric disturbances in real time (Maruyama et al. 2005; Scherliess et al. 2006). The Ey component drives an eastward Pedersen current and a downward Hall current. Inhibition of the Hall current results in the development of a large vertical Hall polarization electric field $(E z)$. As a result, $E z$ induces a strong eastward Hall current, thus enhancing ionospheric conductivity in the equatorial electrojet (EEJ) region (Forbes 1981). Therefore, the EEJ current is strongly dependent on the primary electric field (i.e., $E y$ ), the polarization electric field (i.e., $E z$ ), and ionospheric conductivity (Reddy 1981).

In long-term studies on the equatorial ionosphere, continuous monitoring of $E y$ and $E z$ at all ionospheric 
heights and several longitudinal sectors is necessary. Such monitoring leads to a clearer understanding of the EEJ, E- and F-region irregularities, pre-reversal vertical drift (eastward electric field enhancement), spread-F, and Appleton anomaly. Consequently, the ionospheric electric fields have widely been studied using radars, magnetometers, ionosondes, and satellites for many years (see, for example, Woodman 1972; Singh and Cole 1987; Crain et al. 1993; Fejer and Scherliess 1997; Hysell and Burcham 2000; Fejer et al. 2008; Aveiro et al. 2009a, b; Denardini et al. 2009, 2011, 2013, 2015).

The E-region electric fields (EEF) can be inferred from measurements of the Doppler frequency of type II echoes detected by VHF radars. Type II echoes are observed whenever the density gradient has a positive projection along $E z$. The Doppler frequency of type II echoes is proportional to $E z$, which is related to $E y$ through the ionospheric conductivities (Cohen 1973; Reddy 1977).

Hall and Pedersen ionospheric conductivities can be computed entirely from the classical conductivity equations reviewed by Forbes (1981), collision frequency expressions given by Bailey and Balan (1996), neutral atmosphere constituents provided by the Mass Spectrometer and Incoherent Scatter Model (Picone et al. 2002), NRLMSISE-00 (hereafter written as MSIS), ionospheric densities based on the International Reference Ionosphere (IRI) model (Bilitza and Reinisch 2008), and the geomagnetic field strength given by the International Geomagnetic Reference Field (IGRF) Model (Finlay et al. 2010). These empirical models, since their first publication, have undergone periodic modifications in attempts to improve their accuracy in representing the neutral atmosphere, ionosphere, and geomagnetic field parameters, respectively, as functions of height, geographic coordinates, local time, and sunspot number. However, these models seem to be less accurate at the equatorial and low-latitude regions in the American sector, a region with diverse electrodynamics and dynamic ionospheric processes, with some being affected by the large magnetic declination angle characteristic of this region (Abdu et al. 1990, 2004). Therefore, it is worth determining the uncertainties (or errors) in the EEF associated with eventual inaccuracies in the MSIS, IRI, and IGRF models. As a result, we can precisely define the confidence limit for the $E y$ and $E z$ estimates. In this report, for the first time, the electric field components estimated from the backscatter coherent radar (RESCO) data are examined in detail with $10 \%$ artificially underestimated and overestimated MSIS-2000, IRI-2007, and IGRF-11 outputs. The corresponding uncertainties in the ionospheric conductivities and electric field estimates are evaluated considering the individual and cumulative contributions of the artificial uncertainties from each model.

\section{Coherent radar, electric field inference, and conductivity model}

In the following sections, we briefly describe the basic operational parameters of the radar for observing $3-\mathrm{m}$ EEJ waves used in this study. The detailed methodology to infer the EEF is also provided. Finally, the magnetic field-line-integrated ionospheric conductivity model, used for $E y$ and $E z$ inference, is described from the original to the current version.

\section{RESCO radar operational parameters}

The RESCO radar westward oblique beam $\left(30^{\circ}\right.$ in zenith angle, geographic coordinates) data collected on February 7, 2001 (reference quiet day for the present study) are analyzed. The radar is located at the São Luís Space Observatory, São Luís, Brazil (SLZ/INPE-MCTI, $2.31^{\circ} \mathrm{S}$, $\left.44.16^{\circ} \mathrm{W}\right)$. It operates at $50 \mathrm{MHz}$, and it is sensitive to the 3 - $\mathrm{m}$ field aligned irregularities. The peak power used for the present experiment was $40 \mathrm{~kW}$. A collinear coaxial (COCO) array antenna is used for transmission and reception. In order to make observations of the daytime E-region irregularities, RESCO operates with pulse width of $20 \mu \mathrm{s}$ and inter-pulse period of $1 \mathrm{~ms}$. Using a sampling gate pulse of constant delay, the time variations of the radar signal parameters corresponding to a fixed radar range have been recorded to cover the height range from about 80 to $120 \mathrm{~km}$, with a height resolution of $2.6 \mathrm{~km}$ and 2-min time resolution. The ranges of radar heights used in this work are as follows: from 101.3 to $103.9 \mathrm{~km}$, centered at $102.5 \mathrm{~km}$; from 103.9 to $106.5 \mathrm{~km}$, centered at $105.1 \mathrm{~km}$; from 106.5 to $109.1 \mathrm{~km}$, centered at $107.7 \mathrm{~km}$; and from 109.1 to $111.7 \mathrm{~km}$, centered at $110.3 \mathrm{~km}$. A detailed description of the RESCO and examples of observations are given by Abdu et al. (2002) and Denardini et al. (2004, 2005, 2006, 2009, 2015).

\section{Methodology to infer the E-region electric fields}

The RESCO data collected on February 7, 2001, revealed the presence of EEJ plasma irregularities from 8 to $18 \mathrm{LT}$. In addition, there were no magnetic disturbances on this day $\left(\sum K p=13^{-}\right)$. Therefore, these data were selected to serve as the probe data in the present study. The purpose of the basic radar data analysis was to determine the representative Gaussian parameters through estimates of the moment similar to that used by Reddy et al. (1987). The Doppler frequency of type II irregularities is obtained from the Gaussian center of frequency distribution and is converted into Doppler velocity $\left(V_{\text {DII }}\right)$ taking into account the RESCO operating frequency and the speed of light. $V_{\mathrm{DII}}$, in turn, is associated with the drift velocity of E-region electrons $\left(V_{\mathrm{e}}\right)$ through the following relation (Reddy 1977):

$$
V_{\mathrm{e}}=V_{\mathrm{DII}}\left(1+\Psi_{0}\right)
$$


where $\Psi_{0}=v_{\text {in }} v_{\mathrm{en}} / \Omega_{\mathrm{i}} \Omega_{\mathrm{e}}$ is known as anisotropic factor, $\nu_{\text {in }}$ and $v_{\text {en }}$ are the ion-neutral and electron-neutral collision frequencies, respectively. The anisotropic factor is $\approx 0.3$ near the center of the EEJ region (Fejer and Kelley 1980). The ions and electron gyro frequencies are calculated by the following expressions:

$$
\begin{aligned}
& \Omega_{\mathrm{i}}=\frac{q_{\mathrm{i}} B}{m_{\mathrm{i}}}, \\
& \Omega_{\mathrm{e}}=\frac{q_{\mathrm{e}} B}{m_{\mathrm{e}}},
\end{aligned}
$$

where $m_{\mathrm{i}, \mathrm{e}}$ is the mass average, $q_{\mathrm{i}, \mathrm{e}}$ is the electrical charge, and $B$ is the Earth's magnetic field flux density. The subscripts $i$ and e indicate ion and electron terms, respectively. The Doppler velocities of type II irregularities are proportional to $E z$, as given in Eq. 3 (Cohen 1973; Reddy 1977):

$$
E z=\frac{V_{\mathrm{DII}}\left(1+\Psi_{0}\right)}{\sin (\Theta)} \frac{B^{2}}{H}
$$

where $\Theta$ is the zenith angle of the radar beam and $H$ is the horizontal component of the geomagnetic field. Physical features of the EEJ were examined by Richmond (1973) using a numerical model, which includes the two-stream instability. He showed that the electric field and current at a given point are strongly dependent on conditions along the entire magnetic field line. Therefore, a conductivity model is used to calculate the Hall $\left(\sigma_{\mathrm{H}}\right)$ and Pedersen $\left(\sigma_{\mathrm{P}}\right)$ conductivities along the magnetic meridian overhead the RESCO radar site, and the field line coordinates with grid resolution of $1 \mathrm{~km}$ in vertical and magnetic north-south directions, in order to infer Ey using Eq. 4 (Richmond 1973):

$$
E_{y}=\frac{\int_{-\theta}^{+\theta} \sigma_{\mathrm{P}} \mathbf{r} \cdot \mathrm{d} \boldsymbol{\theta}}{\int_{-\theta}^{+\theta} \sigma_{\mathrm{H}} \mathbf{r} \cdot \mathrm{d} \boldsymbol{\theta}} \cdot E_{z} \Rightarrow E_{y}=\frac{\Sigma_{\mathrm{P}}}{\Sigma_{\mathrm{H}}} \cdot E_{z} .
$$

In Eq. 4, $\boldsymbol{r}$ is the position of the magnetic field line element considering dipole geometry, $\theta$ is the magnetic latitude, $\mathrm{d} \boldsymbol{\theta}$ is the differential magnetic latitude element vector, and $\Sigma_{\mathrm{H}}$ and $\Sigma_{\mathrm{P}}$ are the Hall and Pedersen field-line-integrated conductivities, respectively.

The diurnal variation of the $E y$ and $E z$ inferred from the RESCO measurement on February 7, 2001, is shown in Fig. 1. The vertical axes are set in $\mathrm{mV} / \mathrm{m}$, and the local time $\left(44^{\circ} \mathrm{W}\right)$ runs along the horizontal axes. The graphs of the figure correspond to the four height ranges centered at 110.3, 107.7, 105.7 and $102.5 \mathrm{~km}$ used in this study (shown on the top right corner of each graph in right panel). The main features of the $E y$ and $E z$ components are: $E y$ shows a diurnal variability that varies from 0.01 to $0.51 \mathrm{mV} / \mathrm{m}$, depending on the height range of the observation. The mean diurnal $E y$ in the four height ranges is $0.22 \pm 0.04 \mathrm{mV} / \mathrm{m}$. The $E z$ component varies from 0.51 to $20.67 \mathrm{mV} / \mathrm{m}$. The mean diurnal $E z$ is $8.12 \pm 1.51 \mathrm{mV} / \mathrm{m}$. The geomagnetic field-line-integrated ionospheric conductivity model used to calculate the ionospheric conductivities in Eq. 4 will be briefly discussed in the next section since it has recently been updated to include more realistic atmospheric parameters.

\section{Magnetic field-line-integrated ionospheric conductivity model}

The magnetic field-line-integrated conductivity model was developed by Denardini (2007). It is essentially composed of: (a) neutral densities and temperature provided by the MSIS model; (b) electron density and ions compositions in the momentum transfer collision frequency equation provided by the IRI model; (c) adjustments to the mean electron density obtained from $f_{0} \mathrm{E}$ at three stations across the magnetic equator to compensate the IRI underestimation of the E-region peak density in the Brazilian sector (Abdu et al. 2004); and (d) geomagnetic field strength and its horizontal component provided by the IGRF model. The summary of the information given in this section is provided in the flowchart of "Appendix." The ion-neutral and electron-neutral collision frequencies were calculated by equations given by Chapman (1956) and Kelley (1989). The model offered results consistent with the conductivity model developed by the Kyoto University. Later, this model was extended (version 2009) to include several ionic and neutral species by Denardini et al. (2013). A new set of ion-neutral and electron-neutral collision frequencies was included, and the momentum transfer collision frequency equation was used to balance these rates (Bailey and Balan 1996; Schunk and Nagy 2004). A further extension of the model (version 2015) includes the daily Ap index (a measurement of the geomagnetic activity related to the space weather) and the F10.7 solar flux, which corresponds to the electromagnetic solar emission at wavelength of $10.7 \mathrm{~cm}$ (equivalent to the $2.8 \mathrm{GHz}$ frequency, measured in $\mathrm{sfu}=10^{-22} \mathrm{~W} \mathrm{~m}^{-2} \mathrm{~Hz}^{-1}$ ). The integrated solar flux density at $10.7 \mathrm{~cm}$ wavelength was used as a proxy for the solar activity due to its known relation to ionizing radiation and terrestrial effects (Chatterjee and Das 1995). Indeed, the F10.7 does not interact with the Earth's atmosphere. It is considered to be a good generalized solar proxy for EUV irradiance (which ionizes it) since the F10.7 originates from the cool corona, a solar region that is closely coupled with magnetic structures responsible for creating the XUV-EUV irradiances (Bruevich et al. 2014). The 81-day average of F10.7 solar flux was included as well. 


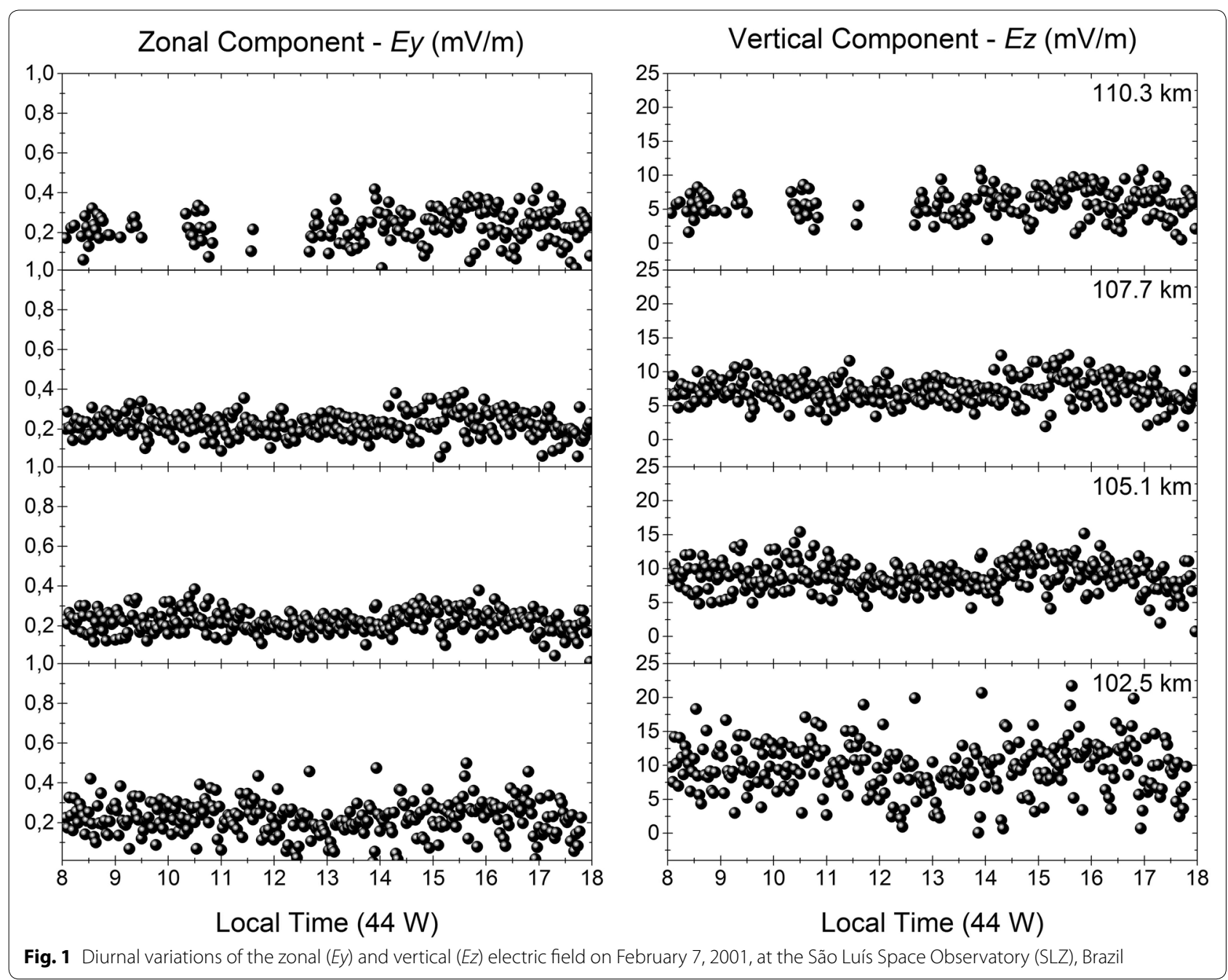

The momentum transfer collision frequency equation for the $i$ th molecular ion (molecular oxygen: $\mathrm{O}_{2}^{+}$, nitric oxide: $\mathrm{NO}^{+}$, atomic oxygen: $\mathrm{O}^{+}$), when the winds and relative velocities between ions are neglected, is (for deductions, see Bailey and Balan 1996):

$g \sin (I)+\frac{k_{\mathrm{B}} T}{m_{\mathrm{i}} N_{\mathrm{i}}} \frac{\partial N_{\mathrm{i}}}{\partial s}+\frac{k_{\mathrm{B}} T}{m_{\mathrm{i}} N_{\mathrm{e}}} \frac{\partial N_{\mathrm{e}}}{\partial s}+\frac{k_{\mathrm{B}}}{m_{\mathrm{i}}} \frac{\partial(2 T)}{\partial s}+\sum_{n} v_{\mathrm{in}}=0$

where $g$ is the acceleration due to gravity, $I$ is the inclination angle of the magnetic field from the horizontal, $k_{\mathrm{B}}$ is the Boltzmann constant, $T$ is neutral temperature, $N_{\mathrm{i}}$ represents ion densities, $N_{\mathrm{e}}$ represents electron density, $s$ is the distance along magnetic field line, and $v_{\text {in }}$ is the collision frequency for momentum transfer between the $i$ th ion and the $n$th neutral gas. The collision frequencies for momentum transfer between ions and electron with neutrals are given in Table 1. These collision frequency expressions are obtained from Bailey and Balan (1996), which describe the Sheffield University Plasmasphere Ionosphere Model (SUPIM). SUPIM has been developed over the last three decades and includes numerous physical and chemical processes of the Earth's mid- and lowlatitude ionosphere and plasmasphere (Bailey et al. 1997). The set of collision frequencies presented in Table 1 was also used to infer the E-region electric fields by Denardini et al. (2013, 2015).

The neutral densities of $\mathrm{O}, \mathrm{O}_{2}$, and $\mathrm{N}_{2}$ are represented by $n(\mathrm{O}), n\left(\mathrm{O}_{2}\right)$, and $n\left(\mathrm{~N}_{2}\right)$, respectively. The electron and ion temperatures were approximated to the neutral temperature, which is possible without significantly affecting the conductivity in the lower E-region (Denardini 2007). The last term in Eq. 5 can be written as $v_{\text {in }}=\sum_{k=1}^{9} v_{k}$, and the electron-neutral collision frequency is the summation of $v_{\mathrm{en}}=\sum_{k=1}^{3} v_{k}$, as shown in the second column in Table 1.

One of the outputs of the geomagnetic field-line-integrated ionospheric conductivity model is the collision 
Table 1 Collision frequencies for momentum transfer between ions and electrons with neutrals $\left(s^{-1}\right)$

$$
\begin{aligned}
& \text { Molecular oxygen }\left(\mathrm{O}_{2}^{+}\right) \text {-neutral } \\
& v_{\mathrm{O}_{2}^{+} \rightarrow \mathrm{O}}=2.31 \times 10^{-10} n(\mathrm{O}) \\
& v_{\mathrm{O}_{2}^{+} \rightarrow \mathrm{O}_{2}}=2.59 \times 10^{-11} n\left(\mathrm{O}_{2}\right) T^{\frac{1}{2}}(1-0.073 \log T)^{2} \\
& v_{\mathrm{O}_{2}^{+} \rightarrow \mathrm{N}_{2}}=4.13 \times 10^{-10} n\left(\mathrm{~N}_{2}\right) \\
& \text { Nitric oxide }\left(\mathrm{NO}^{+}\right) \text {-neutral } \\
& v_{\mathrm{NO}^{+} \rightarrow \mathrm{O}}=2.44 \times 10^{-10} n(\mathrm{O}) \\
& v_{\mathrm{NO}^{+} \rightarrow \mathrm{O}_{2}}=4.27 \times 10^{-10} n\left(\mathrm{O}_{2}\right) \\
& v_{\mathrm{NO}^{+} \rightarrow \mathrm{N}_{2}}=4.34 \times 10^{-10} n\left(\mathrm{~N}_{2}\right) \\
& \text { Atomic oxygen }\left(\mathrm{O}^{+}\right) \text {-neutral } \\
& v_{\mathrm{O}^{+} \rightarrow \mathrm{O}}=4.45 \times 10^{-11} n(\mathrm{O}) T^{\frac{1}{2}}(1.04-0.067 \log T)^{2} \\
& v_{\mathrm{O}^{+} \rightarrow \mathrm{O}_{2}}=6.64 \times 10^{-10} n\left(\mathrm{O}_{2}\right) \\
& v_{\mathrm{O}^{+} \rightarrow \mathrm{N}_{2}}=6.82 \times 10^{-10} n\left(\mathrm{~N}_{2}\right) \\
& \text { Electron-neutral } \\
& v_{\mathrm{e} \rightarrow \mathrm{O}}=8.9 \times 10^{-11} n(\mathrm{O})\left(1+5.7 \times 10^{-4} T\right) T^{\frac{1}{2}} \\
& v_{\mathrm{e} \rightarrow \mathrm{O}_{2}}=1.82 \times 10^{-10} n\left(\mathrm{O}_{2}\right)\left(1+3.6 \times 10^{-2} T^{\frac{1}{2}}\right) T^{\frac{1}{2}} \\
& v_{\mathrm{e} \rightarrow \mathrm{N}_{2}}=2.33 \times 10^{-11} n\left(\mathrm{~N}_{2}\right)\left(1-1.21 \times 10^{-4} T\right) T
\end{aligned}
$$

frequencies for ions and electrons with neutral gas as functions of altitude. Figure 2 shows an example of the variations of the ion (continuous line) and electron (dashed lines) collision frequencies at $12 \mathrm{LT}$ on February 7, 2001, without introducing any uncertainty, i.e., using the standard values provided by the composing model. It is seen that in the lower E-region $(90 \mathrm{~km}), v_{\mathrm{en}}$ is higher than $3 \times 10^{6} \mathrm{~s}^{-1}$ and decreases to about $2 \times 10^{3} \mathrm{~s}^{-1}$ at $130 \mathrm{~km}$. On the other hand, $v_{\text {in }}$ decreases from around to $8 \times 10^{5} \mathrm{~s}^{-1}$ to about $4 \times 10^{2} \mathrm{~s}^{-1}$ in the same height

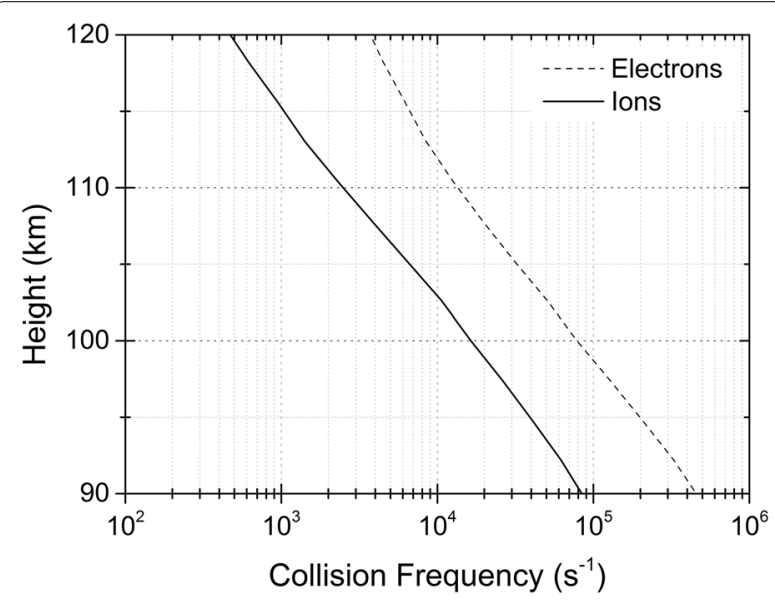

Fig. 2 Vertical profiles of the collision frequencies for ions (continuous line) and electrons (dashed line) with neutral gas as functions of altitude at 12 LT on February 7, 2001, at the São Luís Space Observatory (SLZ), Brazil

range. Therefore, this figure can be taken as an example of the classical behavior of the collision frequency, with the electron-neutral collision frequency $\left(v_{\text {en }}\right)$ always having larger magnitude than the ions-neutral collision frequency $\left(v_{\text {in }}\right)$.

The collision frequency all over the E-region in our model was analyzed, and the typical altitude distribution of the daytime local Hall $\left(\sigma_{\mathrm{H}}\right)$ and Pedersen $\left(\sigma_{\mathrm{P}}\right)$ conductivity, and Hall-to-Pedersen ratio $\left(\sigma_{\mathrm{HP}}\right)$ is presented as color maps between 90 and $120 \mathrm{~km}$ in Fig. 3a (from top to bottom). These maps are essentially vertical profiles of the corresponding quantities grouped in the proper temporal sequence with a time resolution of $2 \mathrm{~min}$ (the same as for the electric fields presented in Fig. 1). Note that a $10^{-4}$ factor of magnitude scale is applied in the local profiles of Hall and Pedersen conductivities. The color scale represents the intensity of the conductivities in $\mathrm{S} / \mathrm{m}$.

As shown, $\sigma_{\mathrm{H}}$ and $\sigma_{\mathrm{P}}$ grow with height due to the decrease in the collision frequencies for both ions and electrons. It is clear that $\sigma_{\mathrm{H}}$ is larger than $\sigma_{\mathrm{P}}$ between 90 and $120 \mathrm{~km}$. The daily peak of $\sigma_{\mathrm{H}}$ occurs from 10:30 to 13:30 LT between 105 and $120 \mathrm{~km}$. Below $100 \mathrm{~km}, \sigma_{\mathrm{H}}$ decreases to $50 \%$ as compared to the maximum intensity at $12 \mathrm{LT}$. At an altitude of $130 \mathrm{~km}$ (not shown here), the Hall conductivity reaches its maximum and then decreases rapidly with height because the drift motion at decreasing collision rates does not lead to charge separation anymore.

The Pedersen conductivity initially increases with height due to decreasing collision frequency. It reaches its maximum at $\sim 150 \mathrm{~km}$ (not shown here) and then gradually decreases to the reduction in collision between particles, leading to a purely drift motion. The local Hallto-Pedersen conductivity ratio shows a maximum of 53 at the central region of the EEJ during the reference day soundings (on February 7, 2001). Field-line-integrated Hall $\left(\Sigma_{\mathrm{H}}\right)$, Pedersen $\left(\Sigma_{\mathrm{P}}\right)$, and Hall-to-Pedersen ratio $\left(\Sigma_{\mathrm{HP}}\right)$ calculated by Eq. 4 are also shown in Fig. 3b. The ratio $\Sigma_{\mathrm{HP}}$ is typically around 25 at $\sim 105 \mathrm{~km}$, decreasing in both downward and upward directions.

\section{Methods}

In the following, we describe the methodology for evaluating the empirical models, which are components of the magnetic field-line-integrated conductivity model, providing most of the variables needed to infer the EEF (from Eqs. 1 to 5). Figure 4 shows a schematic representation of these variables associated with the respective empirical model. In this diagram, the variables provided by each one of the three model dimensions are aligned with one of the three axes lines (named after the model) representing a three-dimensional diagram, which start in the center of the circle and extend to the periphery. 

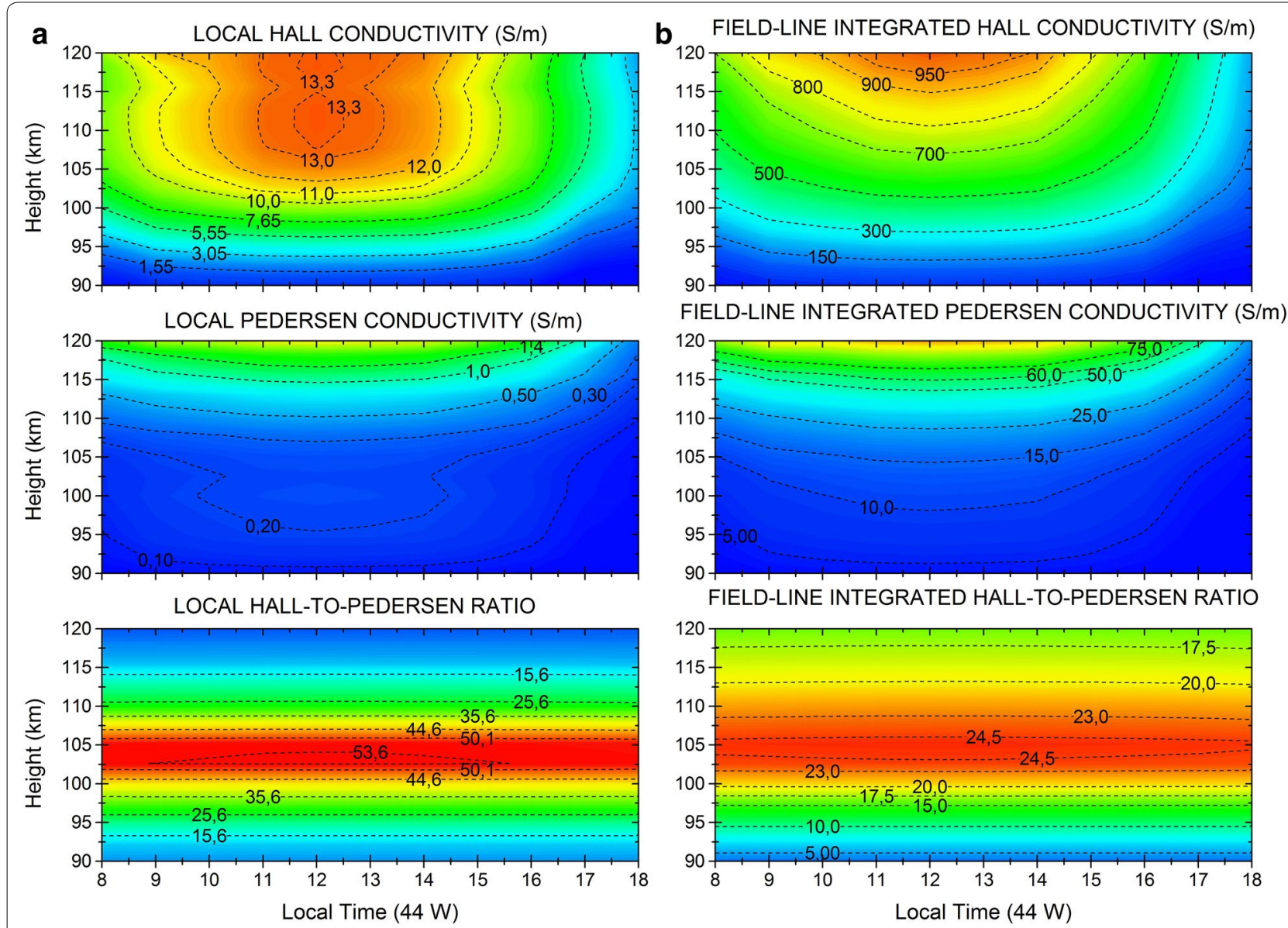

Fig. 3 Local (a) and integrated (b) Hall, Pedersen, and Hall-to-Pedersen ratio (from the top to the bottom) color maps between 90 and $120 \mathrm{~km}$ calculated with the magnetic field-line-integrated conductivity model at 12 LT on February 7, 2001, at the São Luís Space Observatory (SLZ), Brazil. Local Hall and Pedersen conductivities are multiplied by a factor of $10^{4}$

Each axis represents an independent dimension meaning the influence of each empirical model in the resulting electric field. The MSIS dimension label is placed in the vertical axis and the model outputs $T, n(\mathrm{O}), n\left(\mathrm{O}_{2}\right)$, and $n\left(\mathrm{~N}_{2}\right)$ are placed along its axis. Since these variables are used to calculate the electron-neutral and ion-neutral collision frequencies, $\nu_{\text {en }}$ and $\nu_{\text {in }}$ are positioned on this axis as well. The IRI and IGRF dimensions are placed in the clockwise direction in the next two axes. Also, their model outputs, $N_{\mathrm{e}}, N_{\mathrm{i}}$ and $B, H$, are placed along the respective axis. Once $B$ is used to calculate the ions and electron gyro frequencies, $\Omega_{\mathrm{i}}$ and $\Omega_{\mathrm{e}}$ are also located in the IGRF dimension. The terms depending on the three empirical models are placed in the central circle: local conductivities (Hall and Pedersen), field-line-integrated conductivities (Hall and Pedersen), and $E y$ and $E z$ components of the electric fields. As mentioned above, $v_{\mathrm{en}}, v_{\mathrm{in}}, \Omega_{\mathrm{e}}$, and $\Omega_{\mathrm{i}}$ are used to compute the anisotropic factor. Therefore, $\Psi_{0}$ is placed between the IGRF and MSIS in the "IGRFeMSIS" direction. Type II Doppler velocity derived from the EEJ radar soundings is located in the upper left rectangle. They are related to E-region electron drift velocity through Eq. 1.

Considering this three-dimensional diagram, we performed several runs of the magnetic field-line-integrated conductivity model. In each of the runs, the magnitude of the empirical model outputs (the variable over the axis) was artificially increased/decreased by $\pm 10 \%$, and the impact on the $E y$ and $E z$ was evaluated in order to determine the uncertainties associated with the conditions established in that specific run. Accordingly, 12 runs were carried out, with six of them underestimating the model outputs (alone and two-by-two) by $10 \%$ and six others overestimating them. Therefore, the confidence limit of the electric field estimates can be defined in this 3-D system based on such evaluation. 


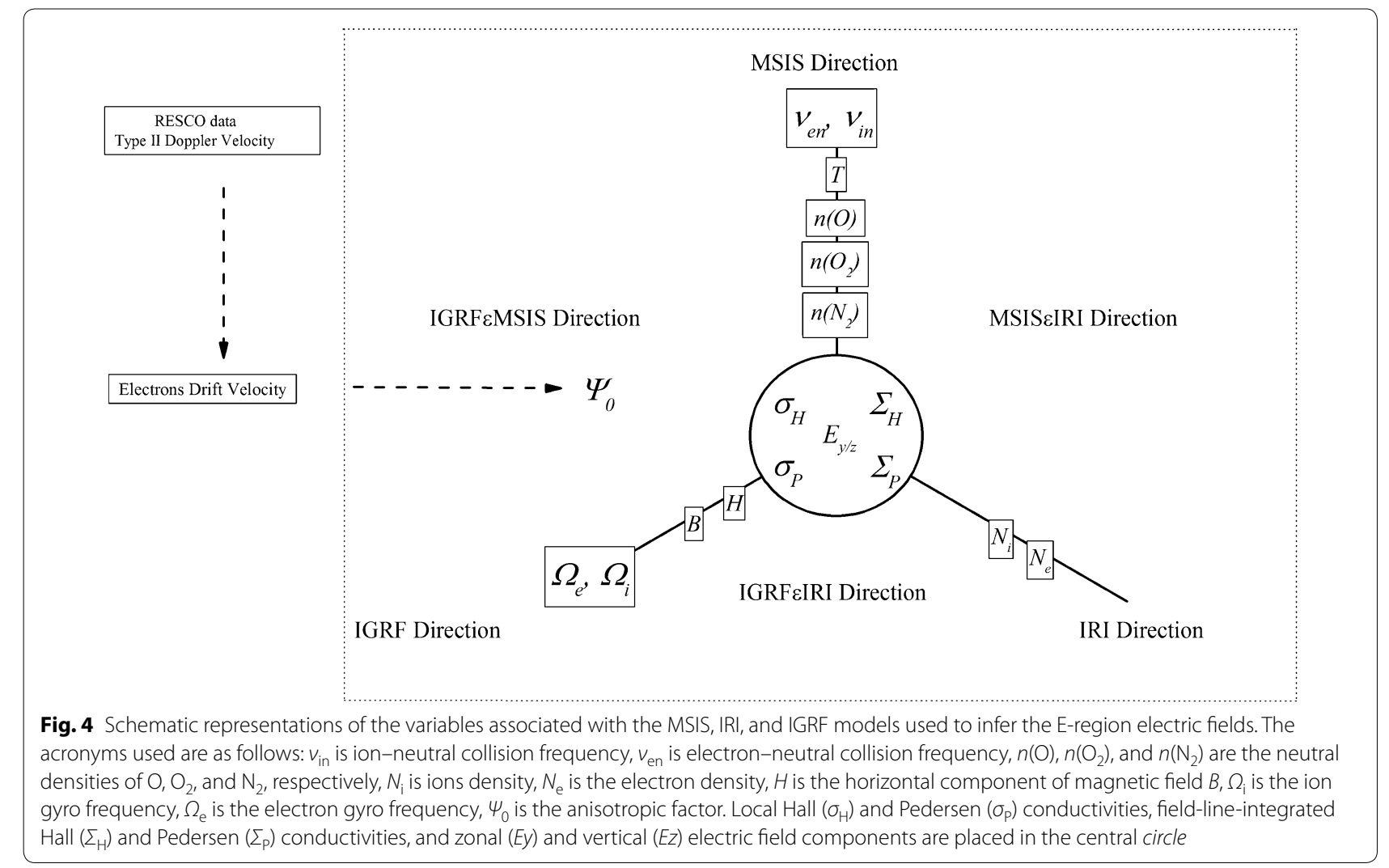

\section{Results}

The results of the 12 runs described in the methodology are given in Table 2.

The first two columns of the table provide information about the modification applied to the amplitude of the variables provided by empirical models composing the geomagnetic field-line-integrated conductivity model during runs. The first column lists the modified models and the second column lists models without any changes in their quantities during the simulation. The subscripts $\mathrm{O}$ and $\mathrm{U}$ indicate that the magnitude of the variables of the composing model was artificially overestimated or underestimated by $10 \%$, respectively. For instance, the first line in Table 2 specifies that $E y$ and $E z$ were inferred when the magnitude of the $T, n(\mathrm{O}), n\left(\mathrm{O}_{2}\right)$, and $n\left(\mathrm{~N}_{2}\right)$ (which are the MSIS outputs) were artificially underestimated $(U)$ by $10 \%$, while the magnitude of the $N_{\mathrm{e}}, N_{\mathrm{i}}$, $B$, and $H$ remained as they were provided by the IRI and IGRF models to that specific run.

The last two columns of Table 2 show the daily averaged percentage variation of the electric field components obtained considering the applied changes on the magnitude of the variables (first column) with respect to the same electric field component with no modification in the variables provided by the MSIS, IRI, and IGRF models, as per the following equations:
Table 2 Results of the $\Delta E y$ and $\Delta E z$ evaluation when variables provided by the MSIS, IRI, and IGRF models are artificially underestimated $(U)$ or overestimated $(O)$ by $10 \%$

\begin{tabular}{|c|c|c|c|}
\hline \multicolumn{2}{|c|}{ Model status during the run } & \multicolumn{2}{|c|}{$\begin{array}{l}\text { Daily averaged uncer- } \\
\text { tainties }\end{array}$} \\
\hline Altered & Constant & $\Delta E y(\%)$ & $\Delta E z(\%)$ \\
\hline $\mathrm{MSIS}_{(U)}$ & $\mid \mathrm{RI}$, IGRF & -9.46 & -9.87 \\
\hline $\mathrm{MSIS}_{(\mathrm{O})}$ & IRI, IGRF & +14.22 & +12.00 \\
\hline MSISEIRI $(\cup)$ & IGRF & -5.25 & -12.58 \\
\hline$M S I S \varepsilon|R|_{(O)}$ & IGRF & +13.39 & +16.89 \\
\hline$|\mathrm{R}|_{(U)}$ & IGRF, MSIS & +3.01 & -3.70 \\
\hline$|\mathrm{R}|_{(\mathrm{O})}$ & IGRF, MSIS & -2.16 & +3.70 \\
\hline$\left.|G R F \varepsilon| R\right|_{(U)}$ & MSIS & +8.47 & +4.11 \\
\hline$\left.|G R F \varepsilon| R\right|_{(O)}$ & MSIS & -6.36 & -3.36 \\
\hline $\operatorname{IGRF}_{(U)}$ & $\mid \mathrm{RI}, \mathrm{MSIS}$ & +6.55 & +8.68 \\
\hline $\operatorname{IGRF}_{(0)}$ & IRI, MSIS & -3.67 & -6.42 \\
\hline IGRFEMSIS $_{(U)}$ & $\mid \mathrm{RI}$ & -6.71 & -3.50 \\
\hline IGRFEMSIS $_{(0)}$ & $\mid \mathrm{RI}$ & +6.96 & +3.49 \\
\hline
\end{tabular}

$$
\begin{aligned}
& \Delta E y=\frac{E y_{\mathrm{U} / \mathrm{O}}-E y}{E y} \times 100, \\
& \Delta E z=\frac{E z_{\mathrm{U} / \mathrm{O}}-E z}{E z} \times 100 .
\end{aligned}
$$


In Eqs. 6a and 6b, $E y$ and $E z$ are the electric field components inferred from the runs with no modification in the variables provided by the MSIS, IRI, and IGRF models, while the $E y_{\mathrm{U} / \mathrm{O}}$ and $E z_{\mathrm{U} / \mathrm{O}}$ are the electric field components inferred from the runs with the variables provided by the models underestimated $(U)$ or overestimated $(O)$ by $10 \%$ according to the indication in the first column. The $\Delta E y$ and $\Delta E z$ are, therefore, considered the daily averaged "uncertainties" introduced in the calculations due to the underestimation or overestimation in the empirical models.

\section{Discussions}

The results presented above were briefly discussed in Denardini et al. (2015) in terms of the simultaneous underestimation and overestimation of the variables provided by the MSIS, IRI, and IGRF models. Now, we focus the discussions in terms of the individual contributions of eventual underestimations and overestimations in the empirical models as well as simultaneous underestimations or overestimations in two out of three models. In addition, we discuss in the following paragraphs the consequences of these uncertainties in the E-region during daytime. We analyze it in terms of the electric fields, changes in ionospheric conductivities during the radar operation, and the linear fit applied between the EEF components inferred on February 7, 2001, and the corresponding components inferred from the 12 simulations $\left(E y_{\mathrm{U} / \mathrm{O}}\right.$ and $\left.E z_{\mathrm{U} / \mathrm{O}}\right)$ given in Table 2.

\section{Analysis of the uncertainties in the electric field components}

From the results presented in Table 2, it is evident that the degree of uncertainties in the variables provided by the empirical models will lead to uncertainties in electric field estimations based on the coherent radar measurements. Also, the variation in the amplitudes of the outputs from some empirical models causes more uncertainties in the electric fields than others. For instance, changes in the amplitude of the variable provided by MSISEIRI $_{(\mathrm{O})}$ lead to much more uncertainty in the electric field components than changes in the amplitude of the variables provided by $\operatorname{IRI}_{(\mathrm{O})}$ alone.

The observed daily averaged uncertainties are highest in runs that involve changes in the amplitude of the variables provided by the MSIS (alone and two-by-two with IRI model: $\operatorname{MSIS}_{(\mathrm{U})}, \mathrm{MSIS}_{(\mathrm{O})}, \mathrm{MSISEIRI}_{(\mathrm{U})}$, and $\left.\operatorname{MSIScIRI}_{(\mathrm{O})}\right)$, lowest when the IRI outputs are changed $\left(\operatorname{IRI}_{(\mathrm{U})}, \operatorname{IRI}_{(\mathrm{O})}\right)$, and moderate in the remaining runs. The higher values in $\Delta E y$ and $\Delta E z$ observed in this analysis are $+14.22 \%$ in the $\mathrm{MSIS}_{(\mathrm{O})}$ run and $+16.89 \%$ in the $\operatorname{MSIScIRI}_{(\mathrm{O})}$, respectively. The lower uncertainties in $\Delta E y$ is $-2.16 \%$ in the $\operatorname{IRI}_{(\mathrm{O})}$ run and in $\Delta E z$ is $3.36 \%$ in the
$\operatorname{IGRFEIRI}_{(\mathrm{O})}$. In regard to changes in the amplitude of the variable provided by the IGRF models, we observed that the electric field components present moderate daily averaged uncertainties. Also, it is seen that out of $12 \mathrm{sim}$ ulations, 3 show uncertainties higher than $10 \%\left(\mathrm{MSIS}_{(\mathrm{O})}\right.$, $\operatorname{MSIScIRI}_{(\mathrm{O})}$, and MSIScIRI $(\mathrm{U})$ and 2 show uncertainties $<5 \%$ in both components $\left(\operatorname{IRI}_{(\mathrm{U})}\right.$ and $\left.\operatorname{IRI}_{(\mathrm{O})}\right)$. It is strongly evidenced that any variation in the MSIS outputs leads to much more uncertainty in the EEF, whereas variations in the IRI outputs cause much smaller effects.

\section{Analysis of diurnal conductivity profiles}

Some implications of the uncertainties coming from the variables provided by the empirical models are more clearly visible by analyzing the Hall-to-Pedersen fieldline-integrated conductivity ratio profiles $\left(\Sigma_{\mathrm{HP}}\right)$, given that this ratio is directly used in Eq. 4. In order to evaluate them, we took the difference of each individual vertical Hall-to-Pedersen field-line-integrated conductivity profile $\left(\Sigma_{\mathrm{HP}}^{*}\right)$ obtained during the 12 runs listed in Table 2 to the corresponding profile obtained with no modification in the variables provided by MSIS, IRI, and IGRF models during the reference day $\left(\Sigma_{\mathrm{HP}}\right)$. Afterward, we grouped the differential profiles in a proper temporal sequence with a time resolution of $2 \mathrm{~min}$, in a similar manner as in the profiles presented in the color map in the bottom panel of Fig. 3b.

Twelve color maps corresponding to the differential analysis of the 12 runs are shown in Fig. 5. The 6 color maps on the left side of the figure correspond to the differential analysis when the variables provided by the empirical models were underestimated during the run. The model being evaluated during the run is identified in the top right corner of each graph in correspondence to the information provided in the first two columns of Table 2. The same applies to the remaining 6 other color maps, but corresponding to the overestimation of the variables. The color bar on the right side of the figure indicates that the absolute difference varies from 0 to 2.5 .

In general, $\Sigma_{\mathrm{HP}}^{*}$ is the highest when the MSIS outputs are artificially underestimated or overestimated by $10 \%$. Indeed, simulations that involve changes in the amplitude of the variables provided by MSIS, such as MSISEIRI and IGRFeMSIS, appear to have consistently larger $\Sigma_{\mathrm{HP}}^{*}$ than those with the MSIS outputs constant, such as IRI, IGRFeIRI, and IGRF runs. Taking the differential analysis results when the variables provided by MSIS are modified, it is seen that $\Sigma_{\mathrm{HP}}^{*}$ is 2.2 in $\mathrm{MSIS}_{(\mathrm{U})}$ and 2 in $\operatorname{MSIS}_{(\mathrm{O})}$, at around $100 \mathrm{~km}$, and decreases in both downward and upward directions of the vertical profile. There is a clear reduction in $\Sigma_{H}^{*}$ when the magnitude of the IRI and IGRF outputs is altered by $\pm 10 \%$. The results show that the difference in the conductivity 


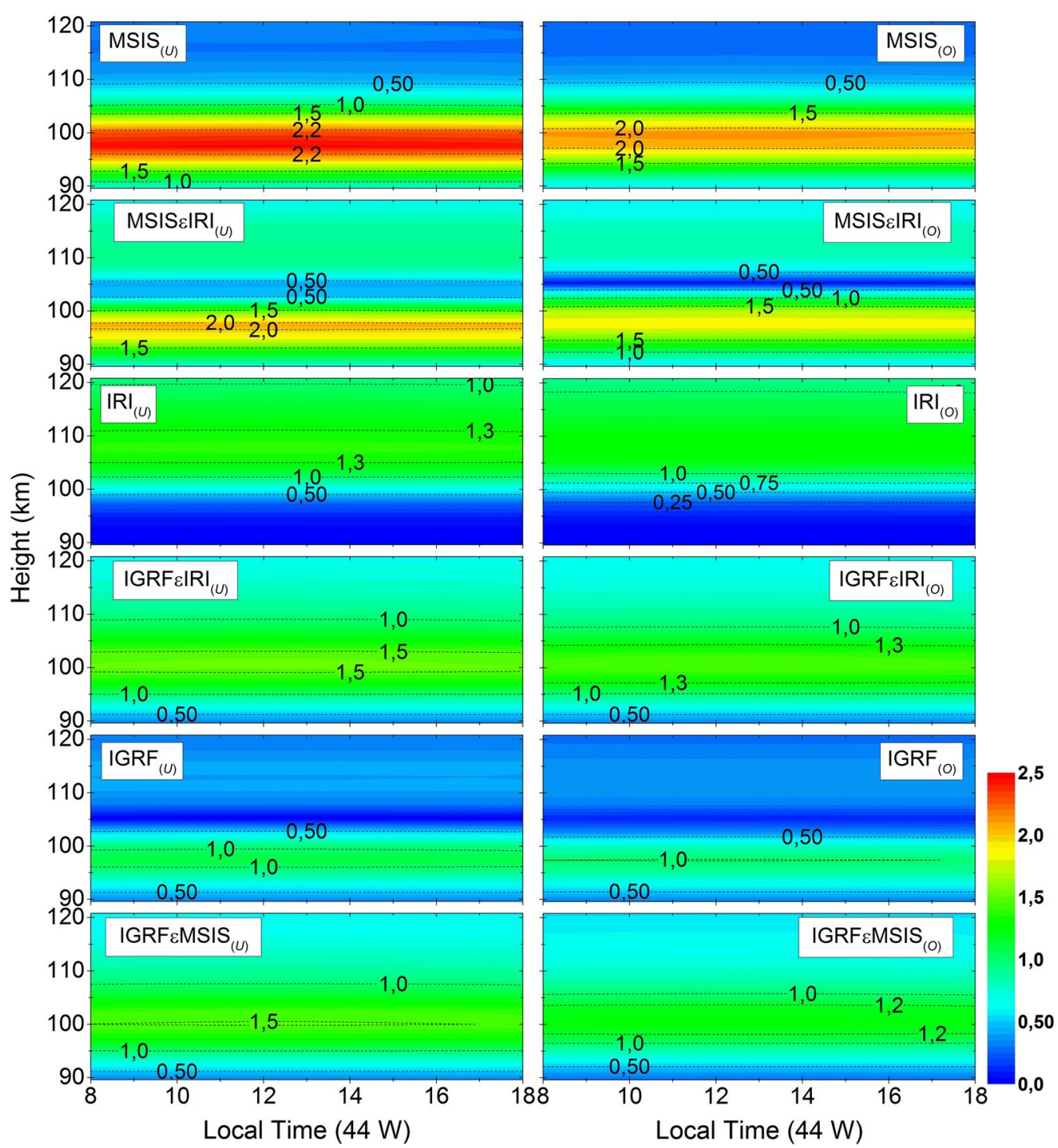

Fig. 5 Absolute differences in the Hall-to-Pedersen conductivity ratio profiles when the variables provided by the empirical models were underestimated (on the left) and overestimated (on the right) in the 12 runs given in Table 2

ratio did not surpass 1.3 when the variables provided by IRI are modified and remained around the unit when the variables provided by IGRF are modified. However, modifications in these two models present opposite effects. The higher values of differential analysis for the IRI evaluation are above $105 \mathrm{~km}$, whereas those for the IGRF evaluation are observed below $105 \mathrm{~km}$. The absolute difference increases when both model outputs are simultaneously varied by $\pm 10 \%$ (IGRFeIRI), leading to changes in the conductivity ratio by up to 1.5 times the original values.

The results above evidenced that higher differences in the EEF and conductivities are observed if neutral densities and neutral temperature provided by the MSIS model are varied, followed by variations in the geomagnetic field given by the IGRF model and variations in electron and ion densities provided by the IRI model. A general investigation of the uncertainties in $\Delta E y$ and $\Delta E z$ involves considering the meaning of the numerator and denominator terms of the anisotropic factor ( $\Psi_{0}$ defined after Eq. 1$)$. It is noticed that the numerator term is the ion-neutral and electron-neutral collision frequencies, calculated from the neutral densities and neutral temperature provided by the MSIS model. The denominator term encompasses the ions and electron gyro frequencies calculated from the magnetic field provided by the IGRF model. An increase (decrease) in the MSIS model is then always accompanied by an increase (decrease) in $E y$ and $E z$, when the 
other quantities remain unaltered. On the other hand, an increase (decrease) in the variables provided by the IGRF model will result in a decrease (increase) in $\Delta E y$ and $\Delta E z$, also considering that the other quantities remain unaltered. It might explain the results obtained for the run $\operatorname{MSIS}_{(\mathrm{U})}, \mathrm{MSIS}_{(\mathrm{O})}, \operatorname{IGRF}_{(\mathrm{U})}$, and $\operatorname{IGRF}_{(\mathrm{O})}$ in Table 2. Furthermore, changes in the IRI model outputs lead to uncertainties up to $3.01 \%$ in $\Delta E y$ and up to $3.70 \%$ in $\Delta E z$ and, the lowest electric field uncertainty obtained in this study resulted from the $\mathrm{IRI}_{(\mathrm{O})}$ run, $-2.16 \%$ in $\Delta E y$. Consequently, we may assume that $\Delta E y$ and $\Delta E z$ are less sensitive to changes in the variables provided by the IRI outputs as compared to the variables provided by the MSIS model. Therefore, it seems fair to attribute the high uncertainties (more than $10 \%$ ) in $\Delta E y$ and $\Delta E z$ obtained in the runs $\operatorname{MSIScIRI}_{(\mathrm{U})}$ and MSISeIRI $(\mathrm{O})$ to the MSIS outputs.

\section{Analysis of linear fitting}

To further investigate the uncertainties associated with the empirical model outputs as a function of height, a linear fitting is applied between $E y$ and $E z$ inferred at the four different radar range heights (Fig. 1) and the corresponding component inferred from the 12 simulations $\left(E y_{\mathrm{U} / \mathrm{O}}\right.$ and $\left.E z_{\mathrm{U} / \mathrm{O}}\right)$, respectively. As a result, we have $\delta E y$ and $\delta E z$ obtained from the slope of the fitted line, which is used to determine the corresponding uncertainties in the electric field estimates, i.e., the amount of changes in $E y_{\mathrm{U} / \mathrm{O}}$ and $E z_{\mathrm{U} / \mathrm{O}}$ compared to $E y$ and $E z$. The results are shown in the charts of Fig. 6 among the three dimensions (MSIS, IRI, and IGRF) and the intermediary directions (MSISeIRI, IGRFeIRI, and IGRFeMSIS) for $\delta E y$ (left panels) and $\delta E z$ (right panels). The dimensions of each empirical model are shown in the three axes, analogous to Fig. 4. The uncertainties in the electric fields due to the eventual errors in the variables provided by the MSIS model alone are placed in the vertical axis. The uncertainties in the electric fields due to eventual errors in the variables provided by the IRI model alone are placed in the axes $120^{\circ}$ clockwise, and the uncertainties in the electric fields due to eventual errors in the variables provided by the IGRF model alone are placed $120^{\circ}$ from both previous axes. All axes are then arranged radially, with equal distances between each other, while maintaining the same scale between all axes defined to have a minimum of $-20 \%$ uncertainties (where the axes intersect) and a maximum of $+40 \%$ uncertainties (outer ring) within a $10 \%$ interval. Grid lines that connect axis to axis are used as a guide. Note that the level of zero percent uncertainty is set to be the second grid line from the center of the chart. The axes are linearly connected so that the uncertainties in the electric fields set can be visualized as a polygon. Finally, the dashed lines/spheres (continuous line-stars) are the uncertainties in the electric fields obtained after underestimating (overestimating) the model outputs by $10 \%$. The labels of the uncertainties are shown in the bottom chart on the left.

Some general characteristics are evident in this slope analysis. For instance, the lower (higher) the radar sounding region of study, the higher (lower) the uncertainties caused by eventual errors in the empirical models. The electric field components inferred from the runs with the variables provided by the models underestimated or overestimated by $10 \%$ change significantly in relation to $E y$ and $E z$. MSIS dimensions present the highest uncertainties at $102.5 \mathrm{~km}$ (lower charts) in both underestimating and overestimating situations, including the MSISEIRI direction. When $E y_{\mathrm{O}}$ increases by $+29.76 \%$ during the MSIS $_{(\mathrm{O})}$ run compared to the $+2.24 \%$ obtained during the IRI $\mathrm{I}_{(\mathrm{O})}$ run, the overestimations in the variables during the MSIScIRI $(\mathrm{O})$ run lead to $34 \%$ changes in $E y_{O}$, which is mostly due to the MSIS model. Also, the EEF has uncertainties around $10 \%$ in the IGRF dimension and no expressive values in the IRI dimension.

It is also notable from the analysis of Fig. 6 that the magnitude of the uncertainties in the electric field decreases in all dimensions in the central region of the EEJ (panels for $105.1 \mathrm{~km}$ ), except for the MSIS dimension, which may lead to higher uncertainties. The smaller uncertainties are located at 107.7 and $110.3 \mathrm{~km}$. It is remarkable that a $10 \%$ reduction (increase) in quantities provided by the models will not impact the electric fields with a reduction (increase) of the same magnitude. As noted from Fig. 6, the lower uncertainties in the EEF are located in the IRI dimension in the higher E-region (107.7 and $110.3 \mathrm{~km}$ ), where changes in the slope are near the level of zero percent uncertainty.

According to the results given in Table 2 and Figs. 5 and 6 , we determined the uncertainties in the conductivity and the EEF associated with the empirical model outputs in order to precisely determine the confidence limit in their magnitude. Although a large number of works deal with the comparisons between neutral atmosphere data and MSIS model prediction (Richards 2002; Liu et al. 2005; Burke et al. 2007; Park et al. 2008; Jeon et al. 2011), observed ionospheric data and IRI model predictions (Abdu et al. 1996; Batista et al. 1996; de Souza et al. 2003; Sethi et al. 2004; Bertoni et al. 2006; Lühr and Xiong 2010; Kenpankho et al. 2011; Oyekola and Fagundes 2012; Yue et al. 2013; Kumar et al. 2014, 2015), and geomagnetic field data and IGRF predictions (Lowes 2000; Lowes and Olsen 2004), uncertainties (or potential errors) of these empirical models have not been published, even in Bilitza and Reinisch (2008), Picone et al. (2002), and Finlay et al. (2010). 


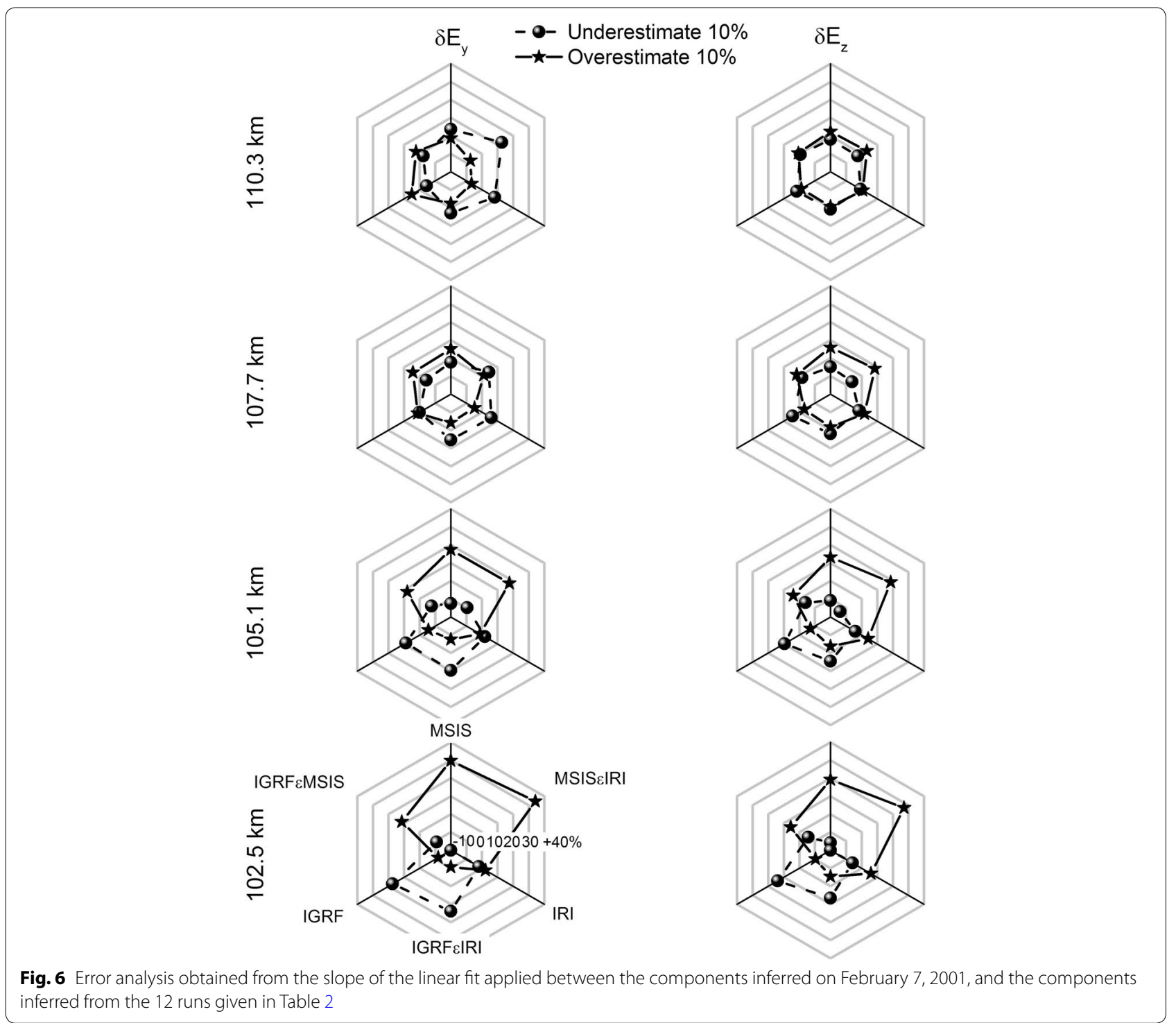

Several authors realized that the empirical models have shortcomings, especially in the equatorial region. However, some of them did not consider the effects of changes in their parameter distributions in their results. They assumed that these empirical models are accurate (e.g., $\mathrm{Du}$ and Stening 1999). Nevertheless, Alken and Maus (2010) were concerned about this issue in their work. The authors developed a technique to estimate the equatorial electric fields from a latitudinal profile of the EEJ current as the CHAMP satellite crossed the magnetic equator. In order to calculate the ionospheric conductivities, the authors used the collision frequency expressions given by Kelley (1989) and the MSIS and IRI models to obtain the neutral densities and the ion and electron densities, respectively. They investigated how daily departures of neutral atmosphere and ionospheric parameters from the climatological mean given by MSIS and IRI models may affect their electric field estimates. Their results show that errors in the neutral density model have small effects in the electric fields derived by satellite data, and they concluded that the main source of uncertainties in the electric fields comes from the IRI model, especially in the calculation of the electron and ion densities. In the present work, the main source of uncertainties in the electric field derived by radar data comes from the MSIS model.

The reasons for the difference between the present work and the interpretation presented by Alken and Maus (2010) can be attributed to the different methodologies 
applied for the radar and satellite data to infer the electric fields. In the present work, the electron density is simplified in the equations when the ratio of Hall to Pedersen conductivities is computed to infer Ey (Eq. 4), minimizing its uncertainties and consequently the errors related to the IRI model. Alken and Maus (2010) modeled and used each of the three components of the ionospheric conductivity (direct, Pedersen, and Hall) to achieve their results (please, see Eq. 14 in their work). Since each component has an electron density dependence, the IRI might become another source of errors. Lühr and Xiong (2010) found that the IRI-2007 model overestimates the electron density by a factor of more than 1.5 in the height range $300-500 \mathrm{~km}$ during the deep solar minimum of solar cycle 23/24. Moreover, different sets of collision expressions were applied in each of these studies to obtain the conductivities. We use the set of expressions found in Bailey and Balan (1996), which are the most updated expressions available in the literature as far as we know, since they are used in the SUPIM model (Bailey et al. 1997). Moreover, the altitude range is different in these works. We studied the influence of uncertainties of the empirical models for inferring the E-region electric fields between 100 and $110 \mathrm{~km}$, while Alken and Maus (2010) (please, see Eq. 9 in their work) focused on an altitude range of $65-465 \mathrm{~km}$. Therefore, the evidences provided in this work show that the MSIS model is responsible for the largest change in $E y$ and $E z$ inferred from the radar data, and the IRI model is responsible for the largest change in Ey inferred from satellite data. Therefore, it is difficult to judge whether IRI and MSIS models are best or worst without a detailed discussion about the methodology applied in the work.

The MSIS, IRI, and IGRF models have been used by the scientific community for many years in diverse areas for a wide range of objectives. The models have been validated in several works and in several longitude sectors and geomagnetic conditions against experimental data in order to improve its accuracy in representing the neutral atmosphere, ionosphere, and geomagnetic field parameters. However, these models appear to be less accurate in the equatorial and low-latitude regions in the American sector due to the effects of some complex processes, which provide unique challenges for empirical modeling of the region. As there are no other empirical models available for the Brazilian equatorial region, it is assumed that their results are the best information available for the neutral atmosphere, ionosphere, and geomagnetic field. However, the reliability of these empirical models has to be considered when evaluating their outputs. The present study provides such an estimation of their accuracies for EEF inferred from the Doppler shifts of type II echoes measured by coherent radars, and the disparities pointed out here will be helpful for advancement of the MSIS, IRI, and IGRF models, especially over equatorial latitudes, where ionospheric data from this region are quite scarce.

\section{Conclusions}

The applications of empirical models have been extending to diverse areas, and they have been in use for a wide range of objectives since the last decades. Researchers usually use the models with no deep investigation about the influence of their uncertainties on the results. Using Doppler shifts of type II echoes measured by the RESCO radar, we have shown, for the first time, the influence of uncertainties of the MSIS-2000, IRI-2007, and IGRF-11 model outputs in the diurnal profiles of the ionospheric conductivity and the E-region electric fields for the Brazilian equatorial region. One of the most significant results of this study is that the variations in $\mathrm{O}, \mathrm{N}_{2}$, and $\mathrm{O}_{2}$ densities and neutral temperature provided by the MSIS2000 cause the largest changes in the E-region conductivity and electric fields. It is observed that the electric fields can differ by almost $40 \%$ if the empirical models have $\pm 10 \%$ errors in their output parameters. The effects are higher in the lower E-region (below $105 \mathrm{~km}$ ). Uncertainties in the geomagnetic field strength and its horizontal component provided by the IGRF-11 lead to smaller effects, followed by electron and $\mathrm{O}_{2}{ }^{+}, \mathrm{NO}^{+}$, and $\mathrm{O}^{+}$ densities given by the IRI-2007. Further research on this topic includes analyses of the empirical model outputs in the F-region and outputs provided by the IRI-2012, the new version of the IRI model.

\section{Authors' contributions}

JM and CMD designed the study, analyzed, and interpreted the data and wrote the manuscript. LCAR, SSC, and NJS helped to improve the manuscript. All authors read and approved the final manuscript.

\section{Author details \\ ${ }^{1}$ Southern Regional Space Research Center (CRS/INPE), Av. Roraima, 5021, Santa Maria, RS 97110-970, Brazil. ${ }^{2}$ National Institute for Space Research (INPE), Av. dos Astronautas, 1758, São José dos Campos, SP 12227-010, Brazil. \\ Acknowledgements \\ J. Moro thanks CNPq/MCTI (Grant 312775/2015-6). C. M. Denardini thanks CNPq/MCTI (Grant 303121/2014-9) and FAPESP (Grant 2012/08445-9). L. C. A. Resende thanks FAPESP (Grant 2014/11198-9). S. S. Chen thanks CNPq/MCTI (Grant 312730/2015-2).}

\section{Competing interests}

The authors declare that they have no competing interests. 


\section{Appendix}

Flowchart of the magnetic field-line-integrated iono-

spheric conductivity model.

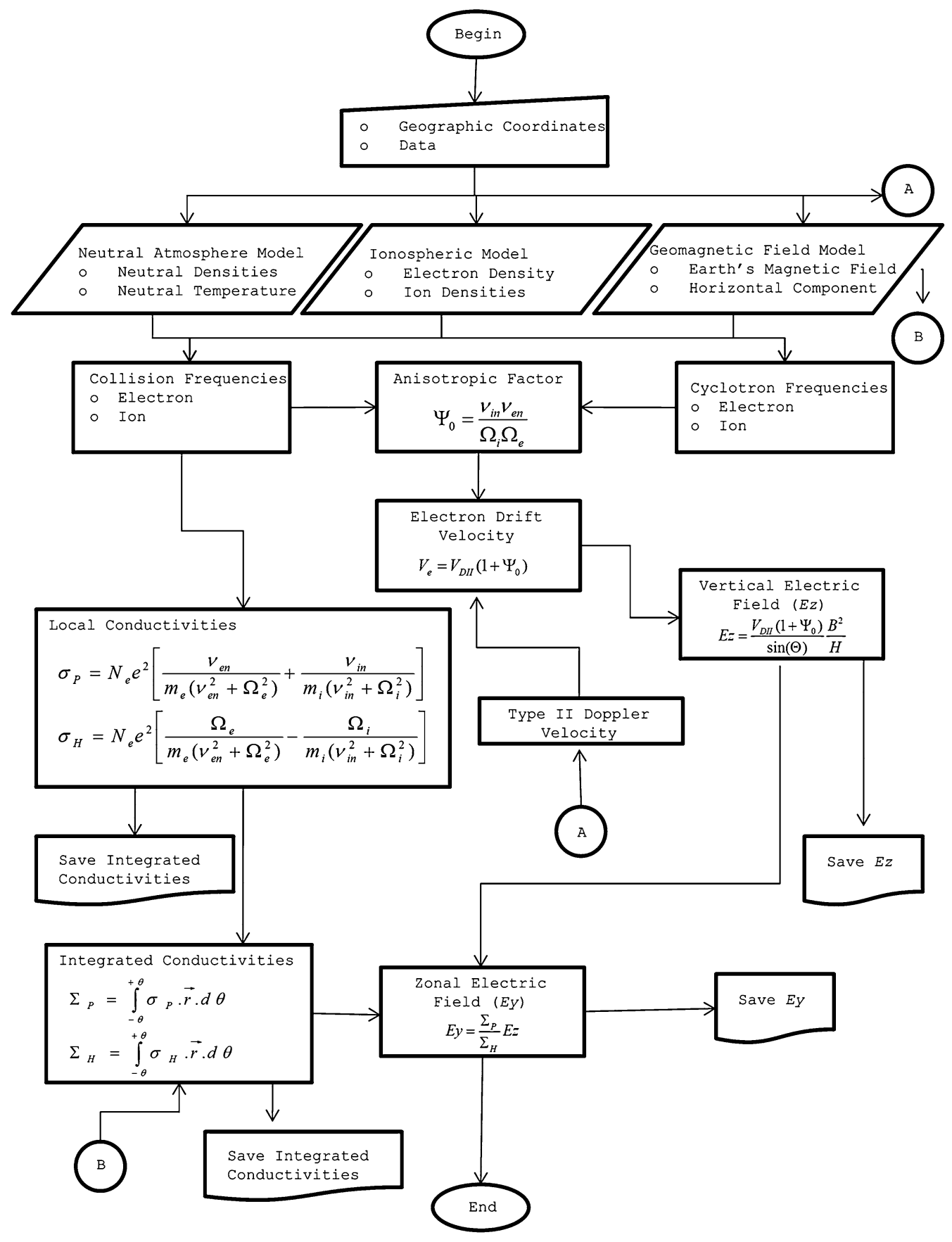


Received: 10 December 2015 Accepted: 25 May 2016 Published online: 07 June 2016

\section{References}

Abdu MA, Muralikrishna P, de Paula ER, Kantor IJ (1990) Rocket-borne measurements of equatorial ionospheric electron densities and their comparison with $\mid \mathrm{RI}-10$ predictions. Adv Space Res 8:41-44

Abdu MA, Batista IS, de Souza JR (1996) An overview of IRI-observational data comparison in American (Brazilian) sector low latitude ionosphere. Adv Space Res 18:13-22

Abdu MA, Denardini CM, Sobral JHA, Batista IS, de Paula ER (2002) Equatorial electrojet irregularities investigations using a $50 \mathrm{MHz}$ back-scatter radar and a digisonde at São Luís: some initial results. J Atmos Sol-Terr Phys 64:1425-1434

Abdu MA, Batista IS, Reinisch BW, Carrasco AJ (2004) Equatorial F-layer heights, evening prereversal electric field, and night E-layer density in the American sector: IRI validation with observations. Adv Space Res 34(9):1953-1965

Alken P, Maus S (2010) Electric fields in the equatorial ionosphere derived from CHAMP satellite magnetic field measurements. J Atmos Sol-Terr Phys 72:31-326

Aveiro HC, Denardini CM, Abdu MA (2009a) Climatology of gravity wavesinduced electric fields in the equatorial E region. J Geophys Res 114:A11308. doi:10.1029/2009JA014177

Aveiro HC, Denardini CM, Abdu MA (2009b) Signatures of 2-day wave in the E-region electric fields and their relationship to winds and ionospheric currents. Ann Geophys 27:631-638

Bailey GJ, Balan N (1996) A low latitude ionosphere-plasmasphere model. In: Schunk RW (ed) STEP hand book of ionospheric models. Utah State Uni., Logan, pp 173-206

Bailey GJ, Balan N, Su YZ (1997) The Sheffield University plasmasphere ionosphere model — a review. J Atmos Solar-Terr Phys 59:1541-1552

Batista IS, Abdu MA, de Medeiros RT, de Paula ER (1996) Comparison between $\mid \mathrm{RI}$ predictions and digisonde measurements at low latitude station. Adv Space Res 18:49-52

Bertoni F, Sahai Y, Lima WLC, Fagundes PR, Pillat VG, Becker-Guedes F, Abalde JR (2006) IRI-2001 model predictions compared with ionospheric data observed at Brazilian low latitude stations. Ann Geophys 24:2191-2200

Bilitza D, Reinisch B (2008) International reference ionosphere 2007: improvements and new parameters. Adv Space Res 42:599-609

Bruevich EA, Bruevich W, Yakunina GV (2014) Changed relation between solar 10.7$\mathrm{cm}$ radio flux and some activity indices which describe the radiation at different altitudes of atmosphere during cycles 21-23. J Astrophys Astron 35:1-15

Burke WJ, Huang CY, Marcos FA, Wise JO (2007) Interplanetary control of thermospheric densities during large magnetic storms. J Atmos Solar-Terr Phys 69:279-287

Chapman S (1956) The electrical conductivity of the ionosphere: a review. Nuovo Cimento (1955-1965) 4:1385-14124

Chatterjee TN, Das TK (1995) Relation between solar UV flux and 10.7-cm radio-emission. Mon Not R Astron Soc 274:858-860

Cohen R (1973) Phase velocities of irregularities in the equatorial electrojet. J Geophys Res 78:2222-2231

Crain DJ, Heelis RA, Bailey GJ, Richmond AD (1993) Low-latitude plasma drifts from a simulation of the global atmospheric dynamo. J Geophys Res 98:6039-6046

de Souza JR, Bailey GJ, Abdu MA, Batista IS (2003) Comparison of low latitude $F$ region peak densities, heights and equatorial ExB drift from $|R|$ with observational data and the Sheffield University plasmasphere ionosphere model. Adv Space Res 31:501-505

Denardini CM (2007) A conductivity model for the Brazilian equatorial E-region: initial results. Braz J Geophys 25:87-94

Denardini CM, Abdu MA, Sobral JHA (2004) VHF radar studies of the equatorial electrojet 3-m irregularities over São Luís: day-to-day variabilities under auroral activity and quiet conditions. J Atmos Sol-Terr Phys 66:1603-1613

Denardini CM, Abdu MA, de Paula ER, Sobral JHA, Wrasse CM (2005) Seasonal characterization of the equatorial electrojet height rise over Brazil as observed by the RESCO $50 \mathrm{MHz}$ back-scatter radar. J Atmos Sol-Terr Phys $67 \cdot 1665-1673$
Denardini CM, Abdu MA, de Paula ER, Wrasse CM, Sobral JHA (2006) VHF radar observations of the dip equatorial E-region during sunset in the Brazilian sector. Ann Geophys 24:1617-1623

Denardini CM, Abdu MA, Aveiro HC, Resende LCA, Almeida PDSC, Olívio EPA, Sobral JHA, Wrasse CM (2009) Counter electrojet features in the Brazilian sector: simultaneous observation by radar, digital sounder and magnetometers. Ann Geophys 27:1593-1603

Denardini CM, Aveiro HC, Almeida PDSC, Resende LCA, Guizelli LM, Moro J, Sobral JHA, Abdu MA (2011) Daytime efficiency of different time scale prompt penetration electric fields to equatorial latitudes. J Atmos Sol-Terr Phys 73:1555-1559

Denardini CM, Aveiro HC, Sobral JHA, Bageston JV, Guizelli LM, Resende LCA, Moro J (2013) E region electric fields at the dip equator and anomalous conductivity effects. Adv Space Res 51:1857-1869. doi:10.1016/j. asr.2012.06.003

Denardini CM, Moro J, Resende LCA, Chen SS, Schuch NJ, Costa JER (2015) E-region electric field dependence of the solar activity. J Geophys Res. doi 10.1002/2015JA021714

Du J, Stening RJ (1999) Simulating the ionospheric dynamo-l. Simulation model and flux tube integrated conductivities. J Atmos Sol-Terr Phys 61:913-923

Fejer BG (1997) The electrodynamics of the low-latitude ionosphere: recent results and future challenges. J Atmos Sol-Terr Phys 59:1456-1482

Fejer BG, Kelley MC (1980) lonospheric irregularities. Rev Geophys Space Phys 18:401-454

Fejer BG, Scherliess L (1997) Empirical models of storm time equatorial zonal electric fields. J Geophys Res 102:24047-24056

Fejer BG, Jensen JW, Su SY (2008) Quiet-time equatorial F region vertical plasma drift model derived from ROCSAT-1 observations. J Geophys Res 113:A05304. doi:10.1029/2007JA012801

Finlay CC, Maus S, Beggan CD, Bondar TN, Chambodut A, Chernova TA, Chulliat A, Golovkov VP, Hamilton B, Hamoudi M, Holme R, Hulot G, Kuang W, Langlais B, Lesur V, Lowes FJ, Lühr H, Macmillan S, Mandea M, Mclean S, Manoj C, Menvielle M, Michaelis I, Olsen N, Rauberg J, Rother M, Sabaka TJ, Tangborn A, Tøffner-Clausen L, Thébault E, Thomson AWP, Wardinski I, Wei Z, Zvereva TI (2010) International geomagnetic reference field: the eleventh generation. Geophys J Int 183:1216-1230

Forbes JM (1981) The equatorial electrojet. Rev Geophys 19:469-504

Hysell DL, Burcham JD (2000) lonospheric electric field estimates from radar observations of the equatorial electrojet. J Geophys Res 105:2443-2460

Jeon HS, Cho S, Kwak YS, Chung JK, Park JU, Lee DK, Kuzmicz-Cieslak M (2011) Mass density of the upper atmosphere derived from Starlette's Precise Orbit determination with satellite laser ranging. Astrophys Space Sci 332:341-351

Kelley MC (1989) The Earth's lonosphere. Plasma physics and electrodynamics. Academic Press, San Diego

Kenpankho P, Watthanasangmechai K, Supnithi P, Tsugawa T, Maruyama T (2011) Comparison of GPS TEC measurements with IRI TEC prediction at the equatorial latitude station, Chumphon, Thailand. Earth Planets Space 63:365-370

Kumar S, Tan EL, Razul SG, See CMS, Siingh D (2014) Validation of the IRI-2012 model with GPS-based ground observation over a low-latitude Singapore station. Earth Planets Space 66:17

Kumar S, Tan EL, Murti DS (2015) Impacts of solar activity on performance of the IRI-2012 model predictions from low to mid latitudes. Earth Planets Space 67:42

Liu H, Luhr H, Henize V, Köhler W (2005) Global distribution of the thermospheric total mass density derived from CHAMP. J Geophys Res. doi:10.1029/2004JA010741

Lowes FJ (2000) An estimate of the errors of the IGRF/DGRF fields 1945-2000. Earth Planets Space 52:1207-1211

Lowes FJ, Olsen N (2004) A more realistic estimate of the variances and systematic errors in spherical harmonic geomagnetic field models. Geophys J Int 157(3):1027-1044

Lühr H, Xiong C (2010) IRI-2007 model overestimates electron density during the 23/24 solar minimum. Geophys Res Lett 37:L23101. doi:10.1029/201 OGL045430

Maruyama N, Richmond AD, Fuller-Rowell TF, Codrescu MV, Sazykin S, Toffoletto FR, Spiro RW, Millward GH (2005) Interaction between direct penetration and disturbance dynamo electric fields in the storm-time equatorial ionosphere. Geophys Res Lett 32:L17105. doi:10.1029/200 5GL023763 
Oyekola OS, Fagundes PR (2012) Equatorial F2-layer variations: comparison between F2 peak parameters at Ouagadougou with the IRI-2007 model. Earth Planets Space 64:553-566

Park J, Moon YJ, Kim KW, Cho KS, Kim HD, Kwak WS, Kim YH, Park YD, Yi Y (2008) Comparison between the KOMPSAT-1 drag derived density and the MSISE model density during strong solar and/or geomagnetic activities. Earth Planets Space 60:601-606

Picone JM, Hedin AE, Drop DP (2002) NRLMSISE-00 empirical model of the atmosphere: statistical comparisons and scientific issues. J Geophys Res 107(A12):1468-1483

Reddy CA (1977) The equatorial electrojet and the associated plasma instabilities. J Sci Ind Res 36:580-589

Reddy CA (1981) The equatorial electrojet: a review of the ionospheric and geomagnetic aspects. J Atmos Terr Phys 43:557-571

Reddy CA, Vikramkumar BT, Viswanathan KS (1987) Electric fields and currents in the equatorial electrojet deduced from VHF radar observations-I. A method of estimating electric fields. J Atmos Terr Phys 49:183-191

Richards PG (2002) Ion and neutral density variations during ionospheric storms in September 1974: comparison of measurement and models. J Geophys Res 107:136
Richmond AD (1973) Equatorial electrojet-I. Development of a model including winds and instabilities. J Atmos Terr Phys 35:1083-1103

Scherliess L, Schunk RW, Sojka JJ, Thompson DC, Zhu L (2006) Utah State University Global Assimilation of lonospheric Measurements Gauss-Markov Kalman filter model of the ionosphere: model description and validation. J Geophys Res. doi:10.1029/2006JA011712

Schunk RW, Nagy AF (2004) lonospheres: physics, plasma physics, and chemistry. Cambridge University Press, Cambridge

Sethi NK, Dabas RS, Vohra VK (2004) Diurnal and seasonal variations of HmF2 deduced from digital ionosonde over New Delhi and its comparison with IRI 2001. Ann Geophys 22:453-458

Singh A, Cole KD (1987) A numerical model of the ionospheric dynamo-II. Electrostatic field at equatorial and low latitudes. J Atmos Terr Phys 49:529-537

Woodman RF (1972) East-west ionospheric drifts at the magnetic equator. Space Res XII:969-974

Yue X, Schreiner WS, Rocken C, Kuo YH (2013) Validate the IRI2007 model by the COSMIC slant TEC data during the extremely solar minimum of 2008. Adv Space Res 51:647-653

\section{Submit your manuscript to a SpringerOpen ${ }^{\circ}$ journal and benefit from:}

- Convenient online submission

- Rigorous peer review

- Immediate publication on acceptance

- Open access: articles freely available online

- High visibility within the field

- Retaining the copyright to your article 